\title{
HUBUNGAN PERENCANAAN PENDIDIKAN \\ DENGAN ASPEK SDM DAN SUMBER DAYA KEUANGAN \\ Fatkhul Mubin \\ fatkhulmubin90@gmail.com
}

\section{A. Latar Belakang}

Pendidikan merupakan ujung tombak dari keerhasilan, maka pendidikan pun rus direncanakan sebelum dilaksanakan agar memperoleh hasil apa yang diharapkan. Jika pendidikan di ebuah negara itu berhasil maka kemajuan emakin pesat, akan tetapi sebaliknya jika pendidikan itu gagal maka negara itu akan mengalami kemunduran dan ketinggalan.

Untuk meraih keberasilan dalaam pendidikan tidak lepaslah lepas dari perencanaan, karena dalam perencanaan itu susun target-target atau harapan-harapan dan metode-metode yang digunakan untuk mencapai tujuan pendidikan itu agar menghaikan produk yang makimal.1

\footnotetext{
1 Saihu, S. (2019). RINTISAN PERADABAN PROFETIK UMAT MANUSIA MELALUI PERISTIWA TURUNNYA ADAM AS KE-DUNIA. Mumtaz: Jurnal Studi Al-Quran dan Keislaman, 3(2), 268-279,

Saihu, S. (2019). Pendidikan Pluralisme Agama: Kajian tentang Integrasi Budaya dan Agama dalam Menyelesaikan Konflik Sosial Kontemporer. Jurnal Indo-Islamika, 9(1), 67-90,

Saihu, S. (2019). IMPLEMENTASI MANAJEMEN BALANCED SCORECARD DI PONDOK PESANTREN JAM'IYYAH ISLAMIYYAH TANGERANG SELATAN. Mumtaz: Jurnal Studi Al-Quran dan Keislaman, 3(1), 1-22.

Saihu, S. (2019). KOMUNIKASI PENDIDIK TERHADAP ANAK BERKEBUTUHAN KHUSUS DI SEKOLAH KHUSUS ASY-SYIFA LARANGAN. Andragogi: Jurnal Pendidikan Islam dan Manajemen Pendidikan Islam, 1(3), 418-440.

Saihu, S., \& Marsiti, M. (2019). PENDIDIKAN KARAKTER DALAM UPAYA MENANGKAL RADIKALISME DI SMA NEGERI 3 KOTA DEPOK, JAWA BARAT. Andragogi: Jurnal Pendidikan Islam dan Manajemen Pendidikan Islam, 1(1), 23-54.

Saihu, S. (2019). KONSEP MANUSIA DAN IMPLEMENTASINYA DALAM PERUMUSAN TUJUAN PENDIDIKAN ISLAM MENURUT MURTADHA MUTHAHHARI. Andragogi: Jurnal Pendidikan Islam dan Manajemen Pendidikan Islam, 1(2), 197-217.

Saihu, S., \& Rohman, B. (2019). PEMBENTUKAN KARAKTER MELALUI MODEL PENDIDIKAN TRANSFROMATIFE LEARNING PADA SANTRI DI PONDOK PESANTREN NURUL IKHLAS BALI. Edukasi Islami: Jurnal Pendidikan Islam, 8(02), 435-452.

Saihu, S., \& Taufik, T. (2019). PERLINDUNGAN HUKUM BAGI GURU. Al Amin: Jurnal Kajian Ilmu dan Budaya Islam, 2(2), 105-116.

Saihu, S. (2020). KONSEP PEMBAHARUAN PENDIDIKAN ISLAM MENURUT FAZLURRAHMAN. Andragogi: Jurnal Pendidikan Islam dan Manajemen Pendidikan Islam, 2(1), 82-95.
} 
Perencanaan dianggap penting karena akan menjadi penentu dan sekaligus memberi arah terhadap tujuan yang ingin dicapai. Dengan demikian suatu kerja akan berantakan dan tidak terarah jika tidak ada perencanaan yang matang dan disusun degan baik akan memberikan pengaruh terhadap ketercapaian tujuan.

Agar hasil perencanaan dapat berjalan lancar maka dapat dikatakan bahwa perencanaan berhubungan dengan aspek yang mempengaruhi pendidikan. Aspek-aspek yang mendukung pendidikan diantaranya adalah, Sumber Daya Manusia, dan Sumber Daya keuangan. Sebagai pendukung pendidikan aspek tersebut sangat diperlukan dalam perencanaan pendidikan agar bagian pendidikan yang direncanakan bisa berkembang secara wajar dan berkembang menjadi lebih baik. Baik dalam tingkat makro, meso, dan mikro.

\section{A. Pembahasan}

\section{Perencanaan Pendidikan dengan Sumber Daya Manusia}

\section{Pengertian Perencanaan Pendidikan}

Ada beberapa definisi tentang perencanaan pendidikan yang dikemukakan oleh beberapa ahli. Dari berbagai pendapat atau definisi yang dikemukan oleh para pakar manajmen. Menurut Yusuf Enoch, perencanaan pendidikan adalah suatu proses yang yang mempersiapkan seperangkat alternatif keputusan bagi kegiatan masa depan yang diarahkan pada pencapaian tujuan dengan usaha yang optimal dan mempertimbangkan kenyataan-kenyataan yang ada di bidang ekonomi, sosial budaya serta menyeluruh suatu Negara. ${ }^{2}$ Menurut Y Dror perencanaan pendidikan adalah suatu proses mempersiapkan seperangkat keputusan untuk kegiatan-kegiatan di masa depan yang di arahkan untuk mencapai tujuan-tujuan dengan cara-cara optimal untuk 
pembangunan ekonomi dan social secara menyeluruh dari suatu Negara. ${ }^{3}{ }_{-}$Menurut Beeby, C.E, perencanaan pendidikan adalah suatu usaha melihat ke masa depan dalam hal menentukan kebijaksanaan prioritas, dan biaya pendidikan yang mempertimbangkan kenyataan kegiatan yang ada dalam bidang ekonomi, social, dan politik untuk mengembangkan potensi system pendidikan nasioanal memenuhi kebutuhan bangsa dan anak didik yang dilayani oleh system tersebut. ${ }^{4}$

Dari beberapa definisi tersebut, kit bisa mengambil keimpulan.Perencanaan Pendidikan adalah suatu proses seperangkat alternatif keputusan bagi kegiatan masa depan untuk mencapai tujuan dengan usaha yang optimal dan mempertimbangkan kenyataan-kenyataan yang ada di bidang ekonomi, sosial budaya serta menyeluruh suatu Negara.5

\section{Pengertian Sumber Daya Manusia}

Sumber daya manusia (SDM) adalah salah satu faktor yang sangat penting bahkan tidak dapat dilepaskan dari sebuah organisasi, baik institusi maupun perusahaan. SDM juga merupakan kunci yang menentukan perkembangan perusahaan. Pada hakikatnya, SDM berupa manusia yang dipekerjakan di sebuah organisasi sebagai penggerak,

\footnotetext{
3 https://goenable.wordpress.com/2012/01/05/definisi-perencanaan-pendidikan.didownload pada hari Selasa tanggal 14 April 2020 jam 17.01 WIB

4 https://winamartiana.wordpress.com/2011/09/25/definisi-perencanaan-pendidikan,didownload pada hari Selasa tanggal 14 April 2020 jam17.08

5 Saihu, S. (2020). ETIKA MENUNTUT ILMU MENURUT KITAB TA'LIM MUTA'ALIM. Al Amin: Jurnal Kajian Ilmu dan Budaya Islam, 3(1), 99-112.

Saihu, Aziz, A., Mubin, F., \& Sarnoto, A. Z. (2020). Design of islamic education based on local wisdom (An analysis of social learning theories in forming character through ngejot tradition in bali). International Journal of Advanced Science and Technology, 29(6), 1278-1293.

Ronaldo, R., Zulfikar, A., Saihu, Ismail, \& Wekke, I. S. (2020). International relations of the asia pacific in the age of trump. Journal of Environmental Treatment Techniques, 8(1), 244-246.

Saihu, M. M., \& Aziz, A. (2020). Implementasi Metode Pendidikan Pluralisme Dalam Mata Pelajaran Pendidikan Agama Islam. Belajea; Jurnal Pendidikan Islam, 5(1), 131-150.

Saihu, M. (2019). Urgensi 'Urf dalam Tradisi Male dan Relevansinya dalam Dakwah Islam di JembranaBali. Jurnal Bimas Islam, 12(1), 173-201.

Saihu, S. (2020). The Effect of Using Talking Stick Learning Model on Student Learning Outcomes in Islamic Primary School of Jamiatul Khair, Ciledug Tangerang. Tarbawi: Jurnal Keilmuan Manajemen Pendidikan, 6(01), 61-68.

Saihu, S. (2020). Pendidikan sosial yang terkandung dalam Surat At-Taubah Ayat 71-72. Edukasi Islami: Jurnal Pendidikan Islam, 9(01), 127-148.
} 
pemikir dan perencana untuk mencapai tujuan organisasi itu ${ }^{6}$ Penegrtian lain dari sumberdaya manusia adalah individu produktif yang bekerja sebagai penggerak suatu organisasi, baik itu di dalam institusi maupun perusahaan yang memiliki fungsi sebagai aset sehingga harus dilatih dan dikembangkan kemampuannya.Sumber daya manusia dibagi dalam dua pengertian. sumber daya manusia secara umum terdiri dari dua yaitu SDM makro yaitu jumlah penduduk dalam usia produktif yang ada di sebuah wilayah, dan SDM mikro dalam arti sempit yaitu individu yang bekerja pada sebuah institusi atau perusahaan. ${ }^{7}$ Pendapat lain, pengertian Sumber daya manusia secara makro adalah penduduk atau warga yang sudah memasuki usia angkatan kerja, baik yang sudah memasuki usia angkatan kerja maupun yang sudah bekerja.Sedangkan pengertian SDM secara mikro adalah orang yang bekerja dan menjadi anggota suatu perusahaan atau institusi yang disebut sebagai karyawan, pegawai, buruh, pekerja, tenaga kerja, dan lain sebagainya. ${ }^{8}$

Dari beberapa pengertian tentag sumber daya manuia, dapatlah diambilkesimpulan :

1) Sumber daya manusia merupakan faktor yag sangat penting dalam sebuah institusi atau perusahaan

2) Sumber Daya manusia merupakan kunci perkembngan institusi atau perusahaan

3) Sumber daya manuia merupakan penggerak, pemikir dan perencana dalam sebuah institusi, organsasi atau perusahaan utuk mencapai tujuan

4) Karena sumber daya manusia itu sebagai penggerak, pemikir dan perencana maka harus dilatih dan dikembngkan.

6. https://id.wikipedia.org/wiki/Sumber_daya_manusia.didownload pada hari Selasa tanggal 14 April 2020 jam 17.42 WIB

7 . https://www.padamu.net/pengertian-sumber-daya-manusia.didownload pada hari Selasa tanggal 14 April 2020 jam 17.46

8 . http://direktoritraining.com/pengertian-sdm/didownload pada hari Selasa tanggal 14 April 2020 jam 17.53 


\section{Hubungan Perencanan Pendidikan dengan Sumber Daya Manusia}

Perencanaan pendidikan masa depan yang efektif dan efisien tentunya meminta tenaga-tenaga yang professional, yaitu para perencana harus merupakan suatu tim multi-disipliner, dan mereka bukan hanya ahli-ahli dalam bidang pendidikan melainkan juga dari disiplin-disiplin dari luar pendidikan, seperti teknik, ekonomi, antropologi, filsafat, dan bidang-bidang lainnya yang relevan. Tentunya yang ideal adalah ahli-ahli pendidikan yang menguasai disiplin ilmu lainnya.9 Dalam transformasi pendidikan, maka tenaga-tenaga perencana yang profesional akan lebih terbuka. Pakar pendidikan dari berbagai disiplin ilmu pengetahuan bisa dididik sebagai tenaga-tenaga perencana pendidikan yang lebih mantap dan professional. Tim perencana yang multi-disipliner, yang menghayati masalahmasalah pendidikan, akan dapat menghayati dan membangun suatu system pendidikan yang relevan dengan tujuan strategis dan misi strategis pembangunan serta dapat mengembangkan materi yang akan disampaikan di dalam proses pembelajaran, serta menguasai tehnik proses pembelajaran itu sendiri.

Proses perencanaan pendidikan yang efektif dan efisien secara mutlak harus ditopang oleh peneliti (riset). Riset yang dibutuhkan adalah dalam dua bidang, yaitu bidang kebijakan dan dalam bidang intern pendidikan. Pelaksanaan riset

\footnotetext{
9 Aziz, A., \& Saihu, S. (2019). Interpretasi Humanistik Kebahasaan: Upaya Kontekstualisasi Kaidah Bahasa Arab. Arabiyatuna: Jurnal Bahasa Arab, 3(2), 299-214

Saihu, S. (2019). PENDIDIKAN KARAKTER BERBASIS KEARIFAN LOKAL (STUDI DI JEMBRANA BALI). Edukasi Islami: Jurnal Pendidikan Islam, 8(01), 69-90.

Şahin, C. RELIGIA.

Saihu, S., \& Mailana, A. (2019). Teori pendidikan behavioristik pembentukan karakter masyarakat muslim dalam tradisi Ngejot di Bali. Ta'dibuna: Jurnal Pendidikan Islam, 8(2), 163-176.

Mubin, F. KEADILAN DALAM GENDER: KAJIAN KEPEMIMPINAN WANITA DALAM ISLAM1,

Saihu, M. (2019). Merawat Pluralisme Merawat Indonesia (Potret Pendidikan Pluralisme Agama Di JembranaBali). Deepublish.

Mubin, F. (2019). TAFSIR EMANSIPATORIS: PEMBUMIAN METODOLOGI TAFSIR PEMBEBASAN. Mumtaz: Jurnal Studi Al-Quran dan Keislaman, 3(1), 131-151. Mubin, F. MODEL-MODEL PEMBELAJARAN BERBASIS MADRASAH DAN KEGIATAN LAIN YANG DIPERLUKAN DI DALAMNYA (FAKTOR PENDUKUNGNYA).
} 
kebijakan pendidikan dapat dilaksanakan oleh badan pemerintah tetapi juga oleh lembaga-lembaga swasta yang independent agar supaya dapat dirumuskan kebijakan-kebijakan dari berbagai arah serta tidak berpihak.

Demikian juga pelaksanaan riset mengenai masalah-masalah pendidikan perlu dilaksanakan oleh lembaga-lembaga pemerintah, misalnya di lingkungan universitas, lembaga-lembaga riset masyarakat dan pakar pendidikan. Dewasa ini dirasakan suatu kelemahan di dalam pengembangan pendidikan nasional karena ketiadaan data riset mengenai masalah-masalah pendidikan yang dibutuhkan oleh masyarakat indonesia sendiri yang sedang berkembang menuju masyarakat adil dan makmur. ${ }^{10}$

Manajemen sumber daya manusia (Human Resource Management) dalam rangka meningkatkan kualitas pendidikan adalah sangat penting, hal ini mengingat bahwa dalam suatu organisasi atau lembaga pendidikan, dapat maju dan berkembang dengan dukungan dari sumber daya manusia. Oleh karena itu setiap lembaga pendidikan atau organisasi yang ingin berkembang, maka harus memperhatikan sumber daya manusia dan mengelolanya dengan baik, agar tercipta pendidikan yang berkualitas. Adapun Sumberdaya Manusia dalam pendidikan meliputi kepala sekolah, tenaga pendidik (guru), karyawan, dan komite sekolah. $^{11}$

Dalam perencanaan SDM tidaklah semudah apa yang dibayangkan, kendati telah ada perhitungan dan pertimbangan berdasarkan kecenderungan dan data yang

10 . http://wahyumirza.blogspot.com/2011/03/perencanaan-sumber-daya-pendidikan.didownloadhari rabu tanggal 15 April 2020 jam 10.59 WIB

11. https://www.kompasiana.com/mahmudrifa.didownloadhari rabu tanggal 15 April 2020

pukul 11.42 WIB 
tersedia. Hal ini wajar karena selain adanya dinamika organisasi juga adanya perubahan faktor lingkungan, kebijakan yang tidak diantisipasi sebelumnya. Proses perencanaan sering tidak berjalan sebagaimana mestinya, karena kebijakan perencanaan tidak dibuat secara detil, sehingga terjadi kesenjangan antara kebijakan sebelumnya dengan aspek teknis operasional secara empiris. Persoalan yang dihadapi dalam perencanaan sumber daya manusia dalam pengembangan dan implementasinya dari strategi sumber daya manusia dapat dikelompokkan ke dalam empat masalah:

1. Perencanaan menjadi suatu problema yang dirasa tidak bermanfaat karena adanya perubahan pada lingkungan eksternal organisasi, meskipun nampak adanya peningkatan kebutuhan bagi perencanaan.

2. Realitas dan bergesernya kaleidoskop prioritas kebijakan dan strategi yang ditentukan oleh keterlibatan interes group yang memiliki power. 3. Kelompok faktor-faktor yang berkaitan dengan sifat manajemen dan ketrampilan serta kemampuan manajer yang memiliki preferensi bagi adatasi pragmatik di luar konseptualisasi, dan rasa ketidakpercayaan terhadap teori atau perencanaan, yang dapat disebabkan oleh kurangnya data, kurangnya pengertian manajemen lini, dan kurangnya rencana korporasi. 4. Pendekatan teoritik konseptual yang dilakukan dalam pengujian kematangan perencanaan sumber daya manusia sangat idealistik dan preskriptif, di sisi lain tidak memenuhi realita organisasi dan cara manajer mengatasi masalah-masalah spesifik.Permasalahan tersebut merupakan sebuah resiko yang perlu adanya antisipasi dengan menerapkan aspek fleksibilitas ,manakala terjadi kesenjangan di lapangan. Namun sedapat mungkin manajer telah menyiapkan langkah-langkah antisipasi secara cermat setiap perkembangan yang terjadi , karena pada dasarnya 
sebuah bangunan perencanaan SDM tidak harus dibongkar secara mendasar, jika ada kekurangan dan kelemahan ,tentu ada upaya mengatasi jalan keluar yang terbaik.. $^{12}$

\section{B. Hubungan Perencanaan dan sumber Daya keuangan}

\section{Pengertian Sumber Daya keuangan}

Sebelum kita membahas hubungan perencanaan pendidikan dan sumber daya keuangan, sebaiknya kita memahami pengertian manajemen keuangan.Ada beberapa pengertian terkait manajemen keuangan. Manajemen keuangan adalah suatu kegiatan perencanaan, penganggaran, pemeriksaan, pengelolaan, pengendalian, pencarian dan penyimpanan dana yang dimiliki oleh suatu organisasi atau perusahaan. ${ }^{13}$ Pengertian lain dari, manajemen Keuangan adalah segala kegiatan atau aktivitas perusahaan yang berhubungan dengan bagaimana cara memperoleh pendanaan modal kerja, menggunakan atau mengalokasikan dana, dan mengelola aset yang dimiliki untuk mencapai tujuan utama perusahaan $^{.14}$

Dari pengertian tersebut dapatlah disimpulkan terkait dengan pengertian manajemen keuangan :

1) suatu proses kegiatan perencanaan pencarian dana yang dimiliki oleh suatu organisasi atau perusahaan.

12. http://wahyumirza.blogspot.com/2011/03/perencanaan-sumber-daya-pendidikan didownload hari Rabu tanggal 15 April 2020 jam 13.50

13 . https://id.wikipedia.org/wiki/Manajemen_keuangan didownload hari Rabu tanggal 15 April 2020 jam 14.20 WIB

14 . https://www.kembar.pro/2015/03/pengertian-fungsi-dan-tujuan-manajemen-keuangan didownload hari rabu tanggal 15 April 2020 jam 14.24 WIB 
2) Suatu proses perencanaan penganggaran dana yang dimiliki oleh suatu organisasi atau perusahaan.

3) Suatu proes perencanan pemeriksaan dana yang dimiliki oleh suatu organisasi atau perusahaan

4) Suatu proes pengelolaan dana yang dimiliki oleh suatu organisasi atau perusahaan.

5) Suatu proses pengendalian dana yang dimiliki oleh suatu organisasi atau perusahaan.

6) Suatu proses pencarian dana yang dimiliki oleh suatu organisasi atau perusahaan.

7) Suatu proes penyimpanan dana yang dimiliki oleh suatu organisasi atau perusahaan.

\section{Hubungan Perencanaan Pendidikan dengan Sumber Daya keuangan}

Sistem Pendidikan Nasional ditetapkan melalui undang-undang berupa Undangundang Republik Indonesia Nomor 2 Tahun 1989 dan ditetapkan pada tanggal 27 Maret 1989. Pada bab VIII pasal 33-36 dijelaskan mengenai sumber daya pendidikan. Kategori pembiayaan pendidikan terdiri dari beberapa bagian:

a. APBN dan APBD merupakan biaya langsung yang terkait dengan penggajian guru, administrator, staf sekolah, pembelian peralatan, materi pelajaran dan gedung sekolah. Dana pendidikan selain gaji dan biaya pendidikan kedinasan dialokasikan minimal 20\% dari APBD. Dana APBD berasal dari APBD Provinsi dan APBD Kabupaten/Kota. Dana tersebut tergantung pada kemampuan keuangan pemerintah setempat dan daerah lain. Dana pendidikan yang berasal dari APBD diperuntukkan sama dengan dana yang berasal dari 
APBN, yakni bisa untuk pendanaan rutin dan untuk pendanaan pembangunan, tergantung pada kebutuhan sekolah. Untuk pendanaan rutin contohnya membayar gaji guru bantu/tenaga honorer. Untuk pendanaan pembangunan direalisasikan untuk rehabilitasi gedung, sarana olahrada dan sejenisnya. Dana APBN pun dapat digunakan untuk Bantuan Operasional Sekolah (BOS) yang setiap daerah mendapatkan jatah yang sama dan dana APBD digunakan untuk Bantuan Operasional Pembangunan (BOP). Sedangkan dana rutin, yaitu dana yang dipakai membiayai kegiatan rutin seperti tambahan gaji guru, pendidikan, penelitian, pengabdian masyarakat, biaya pemeliharaan, dsb.

b. Dana Penunjang Pendidikan berupa beasiswa yang diterima oleh peserta didik untuk menunjang biaya pendidikannya.

c. Dana dari Masyarakat yang berupa bantuan/sumbangan BP3 (sekarang menjadi SPP) yaitu dana untuk peserta didik seperti untuk pembayaran seragam, buku, ATK, transport. Selain sumbangan SPP juga ada dana pembangunan, ialah dana yang dipakai membiayai pembangunan dalam berbagai bidang seperti sarana prasarana, alat belajar, media, dsb.

d. Sumbangan dari Pemerintah Daerah setempat ialah sumbangan yang diterima oleh sekolah dari pemerintah daerah setempat dimana sekolah tersebut berada.

e. Bantuan lain-lain adalah bantuan yang diterima oleh sekolah dari berbagai pihak selain APBN dan APBD, Dana Penunjang Pendidikan, Dana dari Masyarakat, Sumbangan dari Pemerintah Daerah setempat. Bantuan tersebut berasal dari kerjasama sekolah dengan instansi lain atau yang sejenis. Diantaranya ialah bantuan yang berasal dari luar negeri. ${ }^{15}$

15 . http://semangateducationzaid.blogspot.com/2016/06/anggaran-apbn-dalam-perencanaan didownload hari rabu tanggal 15 April 2020 jam 14.48 WIB 
Dalam mengukur biaya pendidikan ada yang dinamakan sebagai total cost dan unit cost. Total cost merupakan biaya pendidikan secara keseluruhan. Sedangkan unit cost adalah biaya satuan per peserta didik. Untuk menentukan biaya satuan terdapat dua pendekatan, yaitu pendekatan makro dan mikro. Pendekatan makro mendasarkan perhitungan pada keseluruhan jumlah pengeluaran pendidikan yang diterima dari berbagai sumber dana kemudian dibagi jumlah murid. Sedangkan pendekatan mikro berdasar pada alokasi pengeluaran per komponen pendidikan yang digunakan peserta $\operatorname{didik}^{16}$.

Untuk menyusun suatu perencanaan pembiayaan atau yang biasa disebut dengan rencana anggaran, hal-hal yang harus diperhatikan :

1) Mengidentifikasi kegiatan-kegiatan yang akan dilakukan selama periode anggaran.

2) Mengidentifikasikan sumber-sumber yang dinyatakan dalam uang, jasa, dan barang.

3) Semua sumber dinyatakan dalam bentuk uang sebab uang pada dasarnya merupakan pernyataan financial.

4) Memformulasikan anggaran dalam bentuk format yang telah disetujui dan dipergunakan oleh instansi tertentu.

5) Menyusun usulan anggaran untuk memperoleh persetujuan pihak yang berwenang.

6) Melakukan revisi usulan anggaran

7) Persetujuan revisi anggaran

8) Pengesahan anggaran

Sumber keuangan dan pembiayaan pada suatu lembaga pendidikan, dapat dikelompokkan dalam tiga sumber, yaitu:

1) Pemerintah, baik pemerintah pusat dan pemerintah daerah, baik yang bersifat umum dan khusus dan diperuntukkan dalam lembaga pendidikan.

2) Orang tua atau peserta didik.

3) Masyarakat.

Biaya yang dikeluarkan dalam suatu anggaran lembaga pendidikan antara lain yaitu biaya rutin adalah biaya yang dikeluarkan dari tahun ketahun, seperti gaji guru, pegawai dalam lembaga

16. Anwar, M.I, Biaya Pendidikan dan Metode Penetapan Biaya Pendidikan. (Jakarta: Mimbar Pendidikan ,1991) hal. 8-33 
pendidikan, biaya operasional, biaya pemeliharaan gedung, fasilitas, alat-alat pengajaran,,biaya pembangunan gedung, dan lain sebagainya.

Anggaran lembaga dalam komponen keuangan harus dilaksanakan dengan baik dan teliti, dari tahap penyusunan anggaran, penggunaan, pengawasan, sesuai dengan aturan dan ketentuan yang berlaku, agar semua anaggaran dapat di manfaatkan secara efektif, efisien, serta bebas dari korupsi.

1) pembelanjaan,

2) prosedur investasi

3) prosedur pemeriksaan

Persoalan penting dalam penganggaran yaitu bagaimana pemanfaatan sumber-sumber secara efisien. Itulah sebabnya penganggaran memerlukan proses yang bertahap. Tahap-tahap yang perlu dilakukan sebagai berikut:

a. Mengidentifikasi kegiatan yang akan dilaksanakan dalam periode anggaran.

b. Mengidentifikasi sumber-sumber yang dinyatakan dalam uang, mesin dan material.

c. Sumber-sumber dinyatakan dalam bentuk uang, sebab anggaran pada dasarnya merupakan pernyataan finansial.

d. Memformulasikan anggaran menurut format yang telah disepakati.

e. Usaha memperoleh persetujuan dari yang berwenang (pengambilan keputusan) dalam tahap ini dilakukankompromi melalui rapat-rapat untuk mempertimbangkan secara objektif dan subjekit. ${ }^{17}$

Hal-Hal Yang Terkait Dalam Perencanaan Anggaran Lembaga Pendidikan ${ }^{18}$

1) Penyusunan Anggaran

Dalam kaitannya dengan proses penyusunan anggaran, dalam buku Manajemen pendidikan, Lipham mengungkapkan 4 fase kegiatan pokok sebagai berikut:

a) Merencanakan anggaran.

17 . http://semangateducationzaid.blogspot.com/2016/06/anggaran-apbn-dalam-perencanaan didownload hari rabu tanggal 15 April 2020 jam 15.00 WIB

18 . Fattah syukur, Manajemen Pendidikan.(Semarang: Pustaka Rizki Putra.2011) hal .114-116 
b) Mempersiapkan anggaran.

c) Mengelola pelaksanaan anggaran.

d) Menilai pelaksanaan anggaran.

2) Proses Anggaran Belanja Sekolah

Ada tiga macam pendekatan tentang penyusunan anggaran belanja yang biasa dipergunakan di sekolah.

a. Comparative approach

1) Melakukan perbandingan laporan atau catatan penerimaan dengan pengeluaran antara satu tahun anggaran dengan tahun anggaran berikutnya.

2) Dalam keputusan anggaran belanja ini didasarkan pada peningkatan tambahan dari satu hal pada waktunya ke hal yang lain.

b. The planning programming budgeting evaluating system approach

1) Menjabarkan tujuan kedalam program-program ke dalam sarana-sarana khusus.

2) Menjabarkan nilai dari masing-masing alternatif.

3) Menjabarkan biaya pelaksanaan dan evaluasi masing-masing program.

c. Function approach

1) Proses anggaran dimulai dari tujuan sekolah.

2) Termasuk dalam pendekatan ini adalah elemen-elemen yang terkandung dalam pendekatan comperative

Anggaran disamping sebagai alat untuk perencanaandan pengendalian, juga merupakan alat bantu bagi manajemen dalam mengarahkan suatu lembaga menempatkan organisasi dalam posisi yang kuat dan lemah. Oleh karena itu, anggraan juga dapat berfungsi sebagai tolak ukur keberhasilan suatu organisasi dalam mencapai sasaran yang telah ditetapkan. Di samping itu, anggaran dapat pula dijadikan alat untuk mempengaruhi 
dan memotivasi pimpinan atau manajer dan karyawan untuk bertindak efisien dalam mencapai sasaran-sasaran lembaga. ${ }^{19}$

1) Anggaran juga berfungsi sebagai alat perencanaan, yang antara lain digunakan untuk:

a) Merumuskan tujuan serta sasaran kebijakan sesuai dengan visi dan misi yang ditetapkan.

b) Merencanakan berbagai program dan kegiatan untuk mencapai tujuan organisasi serta merencanakan alternatif sumber pembiayaan.

c) Mengalokasikan sumber-sumber anggaran pada berbagai program dan kegiatan yang telah disusun.

d) Menentukan indikator kinerja dan tingkat pencapaian strategi.

2) Anggaran berfungsi sebagai alat pengendalian, yang digunakan antara lain:

a) Mengendalikan efisiensi pengeluaran

b) Membatasi kekuasaan dan wewenagan lembaga pendidikan

c) Mencegah adanya overspending dan salah sasaran dalam mengalokasiskan anggaran dalam suatu lembaga pendidikan.

d) Memonitor kondisi keuangan dan peraksanaan operasional program lembaga pendidikan.

- Anggaran sebagai alat kebijakan fiskal digunakan untuk menstabilkan anggaran lembaga dan mondorong kemanjuan dalam kegiatan lembaga pendidikan.

a) Anggaran sebagai alat koordinasi antar unit kerja dalam penyusunan anggaran.

b) Anggaran dapat digunakan sebagai alat evaluasi kinerja. 
c) Anggran dapat digunakan sebagai alat untuk memotivasi manajemen pendidikan agar bekerja secara ekonomi, efektif dan efesien.

Pendapat lain, Anggaran dapat juga sebagai alat untuk menciptakan ruang public, artinya semua jaringan dalam hal pendidikan dapat memberikan manfaat kepada semua bidang pendidikan ${ }^{20}$

Prinsip-prinsip anggaran sebagai berikut:

a) Adanya pembagian wewenang dan tanggung jawab yang jelas dalam system manajemen dan organisasi.

b) Adanya system akuntasi yang memadai dalam melaksanakan anggaran.

c) Adanya penelitian dan analisis untuk menilai kinerja organisasi.

d) Adanya dukungan dari pelaksana mulai dari tingkat atas sampai yang paling bawah.

Persoalan penting dalam penyusunan anggaran adalah bagaimana memanfaatkan dana secara efisisn, mengalokasikan secara tepat, sesuai dengan skala prioritas

Pertimbangan utama dalam pendekatan efektivitas biaya (uang) adalah berapa banyak budget yang tersedia untuk pendidikan, pendidikan apa yang dapat dilakukan dengan budget tersebut. Dalam konteks ini dianut prinsip produktivitas, yakni dengan dana minimal diupayakan dapat mencapai hasil yang maksimal. Para penyelenggara pendidikan akan menghindari adanya Pemborosan dalam pembiayaan pendidikan dan akan berupaya seoptimal mungkin agar tujuan pendidikan dapat dicapai secara cepat dan tepat. ${ }^{21}$

Pemerintah pusat. Peran dukungan dari pemerintah pusat terhadap pembiayaan pendidikan, tidak saja diperlihatkan dalam anggaran Departemen Pendidikan, tetapi juga pada anggaran departemen lainnya yang bertanggung jawab untuk latihan tertentu. Umpamanya, Departemen Tenaga Кегja sering sekali bertanggung jawab untuk latihan tekhnik keterampilan, departemen pertanian untuk latihan pertanian, departemen kessehatan untuk pendidikan juru rawat.

20 . Syaifudin, dkk, .Perencanaan Pendidikan Suatu Pendekatan Komprensif. (Bandung: Remaja Rosdakarya. 2007) hal. 261-263

21. Manap Soemantri, 2014, Perencanaan Pendidikan, Bandung: IPB Pres. Hlm. 6 
Pemerintah daerah. Memegang peranan yang penting dalam pembiayaan pendidikan di negara-negara dengan sistem keuangan yang didesentralisasi seperti Amerika Serikat dan Inggris. Sumbangan mereka jarang dapat diabaikan, sekalipun dalam negara dengan keuangan yang didesentralisasi, seperti Prancis, di mana mereka menanggung sebagian dari biaya sekolah pemerintah di daerah mereka. ${ }^{22}$

Tingkat kelembagaan. Sejalan dengan otonomi daerah yang menyerahkan masalah pendidikan ke daerah dan sekolah masng-masng, maka masalah keuangan pun menjadi kewenangan yang diberian secara langsung dalam pegelolaannya kepada sekolah. Dalam hal ini, kepala sekolah memiliki tanggung jawab penuh terhadap perencanaan, pelaksanaan, evaluasi dan pertanggungjawaban keuangan sekolah.

Lipham sebagaimana disebutkan Mulyasa mengungkapkan empat fase kegiatan pokok penyusunan anggaran sebagai berikut.

\section{1) Perencanaan anggaran}

Perencanaan anggaran merupakan kegiatan mengidentifikasi tujuan, menentukan prioritas menjabarkan tujuan kedalam penampilan operasional yang dapat diukur, menganalisis alternatif pencapaian tujuan dengan analisis cost effectiveness, membuat rekomendasi alternative pendekatan untuk mencapai sasaran.

\section{2) Mempersiapkan anggaran}

Antara lain menyesuaikan kegiatan dengan mekanisme anggaran yang berlaku, bentuknya, distribusi, dan sasaran program pengajaran perlu dirumuskan dengan jelas.

\section{3) Mengelola pelaksanaan anggaran}

Antara lain mempersiapkan pembukaan, melakukan pembelajaran dan membuat transaksi, membuat perhitungan,, mengawasi pelaksanaan sesuai dengan prosedur kerja yang berlaku, serta membuat laporan pertanggung jawaban keuangan. 
4) Menilai pelaksanaan anggaran

Antara lain menilai pelaksanaan proses belajar mengajar, menilai bagaimana pencapaian sasaran program, serta membuat rekomendasi untuk perbaikan anggaran yang akan datang.

Berdasarkan hal tersebut dapat dikemukakan bahwa perencanaan keuangan dapat dikembangkan secara efektif jika didukung oleh beberapa sumber yang esensial, seperti: a) sumberdaya manusia yang kompeten; b) tersedianya informasi yang akurat dan tepat waktu untuk menunjang pembuatan keputusan; c) menggunakan menejemen dan teknologi yang tepat dalam perencanaan; d) tersedianya dana yang memadai untuk menunjang pelaksanaan ${ }^{23}$

\section{Kesimpulan}

Perencanaan berhubungan dengan faktor-faktor yang mempengaruhi pendidikan. Faktor-faktor yang mendukung pendidikan diantaranya adalah sumber daya manuia dan sumber daya keuangan. Sebagai pendukung pendidikan faktor tersebut perlu diperlukan dalam perencanaan pendidikan agar bagian pendidikan yang direncanakan bisa berkembang secara wajar dan berkembang menjadi lebih baik.

23 . Mulyasa, 2005, Menjadi Kepala Sekolah Profesional, Bandung: Remaja Rosda Krya. Hlm. 198-199. 


\section{DAFTAR PUSTAKA}

Anwar, M.I, Biaya Pendidikan dan Metode Penetapan Biaya Pendidikan. (Jakarta: Mimbar Pendidikan ,1991) hal. 8-33

Aziz, A., \& Saihu, S. (2019). Interpretasi Humanistik Kebahasaan: Upaya Kontekstualisasi Kaidah Bahasa Arab. Arabiyatuna: Jurnal Bahasa Arab, 3(2), 299-214

Fattah syukur, Manajemen Pendidikan.(Semarang: Pustaka Rizki Putra.2011) hal .114-116

Fattah, Nanang,, Ekonomi Dan Pembiayaan Pendidikan, (Rosdakarya, Bandung: Rosdakarya.2004). hal.47

http://direktoritraining.com/pengertian-sdm/didownload pada hari Selasa tanggal 14 April 2020 jam 17.53 WIB

http://hidayatkaryadi.blogspot.com.definisi-perencanaan-pendidikan. Didownload pada hari Selasa tanggal 14 April 2020 jam 16.50 WIB

http://semangateducationzaid.blogspot.com/2016/06/anggaran-apbn-dalam-perencanaan didownload hari rabu tanggal 15 April 2020 jam 14.48 WIB

http://semangateducationzaid.blogspot.com/2016/06/anggaran-apbn-dalam-perencanaan didownload hari rabu tanggal 15 April 2020 jam 15.00 WIB http://wahyumirza.blogspot.com/2011/03/perencanaan-sumber-daya pendidikan. didownload

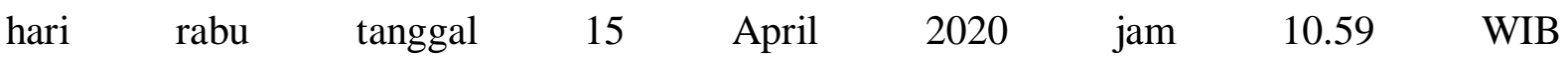
https://www.kompasiana.com/mahmudrifa.didownload hari rabu tanggal 15 April 2020 pukul 11.42 WIB

http://wahyumirza.blogspot.com/2011/03/perencanaan-sumber-daya-pendidikan didownload hari Rabu tanggal 15 April 2020 jam 13.50 WIB https://goenable.wordpress.com/2012/01/05/definisi-perencanaan-pendidikan.didownload pada hari Selasa tanggal 14 April 2020 jam 17.01 WIB 
https://id.wikipedia.org/wiki/Manajemen_keuangan didownload hari Rabu tanggal 15 April 2020 jam 14.20 WIB

https://id.wikipedia.org/wiki/Sumber_daya_manusia.didownload pada hari Selasa tanggal 14 April 2020 jam 17.42 WIB

https://winamartiana.wordpress.com/2011/09/25/definisi-perencanaanpendidikan,didownload pada hari Selasa tanggal 14 April 2020 jam17.08

https://www.kembar.pro/2015/03/pengertian-fungsi-dan-tujuan-manajemen-keuangan

didownload hari rabu tanggal 15 April 2020 jam 14.24 WIB

https://www.padamu.net/pengertian-sumber-daya-manusia.didownload pada hari Selasa tanggal 14 April 2020 jam 17.46 WIB

J. Hallak diterjemahkan oleh Harso, 1985, Analisis Biaya dan Pengeluaran untuk Pendidikan, Jakarta: Bhratara Karya Aksara. Hlm. 23-24.

Manap Soemantri, 2014, Perencanaan Pendidikan, Bandung: IPB Pres. Hlm. 6

Mubin, F. (2019). TAFSIR EMANSIPATORIS: PEMBUMIAN METODOLOGI TAFSIR PEMBEBASAN. Mumtaz: Jurnal Studi Al-Quran dan Keislaman, 3(1), 131-151.

Mubin, F. KEADILAN DALAM GENDER: KAJIAN KEPEMIMPINAN WANITA DALAM ISLAM1,

Mubin, F. MODEL-MODEL PEMBELAJARAN BERBASIS MADRASAH DAN KEGIATAN LAIN YANG DIPERLUKAN DI DALAMNYA (FAKTOR PENDUKUNGNYA).

Mulyasa, 2005, Menjadi Kepala Sekolah Profesional, Bandung: Remaja Rosda Krya. Hlm.

198-199.

Ronaldo, R., Zulfikar, A., Saihu, Ismail, \& Wekke, I. S. (2020). International relations of the asia pacific in the age of trump. Journal of Environmental Treatment Techniques, 8(1), 244-246.

Şahin, C. RELIGIA.

Saihu, Aziz, A., Mubin, F., \& Sarnoto, A. Z. (2020). Design of islamic education based on local wisdom (An analysis of social learning theories in forming character through ngejot tradition in bali). International Journal of Advanced Science and Technology, 29(6), 1278-1293.

Saihu, M. (2019). Urgensi 'Urf dalam Tradisi Male dan Relevansinya dalam Dakwah Islam di Jembrana-Bali. Jurnal Bimas Islam, 12(1), 173-201.

Saihu, M. (2019). Merawat Pluralisme Merawat Indonesia (Potret Pendidikan Pluralisme Agama Di Jembrana-Bali). Deepublish. 
Saihu, M. M., \& Aziz, A. (2020). Implementasi Metode Pendidikan Pluralisme Dalam Mata Pelajaran Pendidikan Agama Islam. Belajea; Jurnal Pendidikan Islam, 5(1), 131-150.

Saihu, S. (2019). IMPLEMENTASI MANAJEMEN BALANCED SCORECARD DI PONDOK PESANTREN JAM'IYYAH ISLAMIYYAH TANGERANG SELATAN. Mumtaz: Jurnal Studi Al-Quran dan Keislaman, 3(1), 1-22.

Saihu, S. (2019). KOMUNIKASI PENDIDIK TERHADAP ANAK BERKEBUTUHAN KHUSUS DI SEKOLAH KHUSUS ASY-SYIFA LARANGAN. Andragogi: Jurnal Pendidikan Islam dan Manajemen Pendidikan Islam, 1(3), 418-440.

Saihu, S. (2019). KONSEP MANUSIA DAN IMPLEMENTASINYA DALAM PERUMUSAN TUJUAN PENDIDIKAN ISLAM MENURUT MURTADHA MUTHAHHARI. Andragogi: Jurnal Pendidikan Islam dan Manajemen Pendidikan Islam, 1(2), 197-217.

Saihu, S. (2019). PENDIDIKAN KARAKTER BERBASIS KEARIFAN LOKAL (STUDI DI JEMBRANA BALI). Edukasi Islami: Jurnal Pendidikan Islam, 8(01), 69-90.

Saihu, S. (2019). Pendidikan Pluralisme Agama: Kajian tentang Integrasi Budaya dan Agama dalam Menyelesaikan Konflik Sosial Kontemporer. Jurnal Indo-Islamika, 9(1), 67-90,

Saihu, S. (2019). RINTISAN PERADABAN PROFETIK UMAT MANUSIA MELALUI PERISTIWA TURUNNYA ADAM AS KE-DUNIA. Mumtaz: Jurnal Studi Al-Quran dan Keislaman, 3(2), 268-279,

Saihu, S. (2020). ETIKA MENUNTUT ILMU MENURUT KITAB TA'LIM MUTA'ALIM. Al Amin: Jurnal Kajian Ilmu dan Budaya Islam, 3(1), 99-112.

Saihu, S. (2020). KONSEP PEMBAHARUAN PENDIDIKAN ISLAM MENURUT FAZLURRAHMAN. Andragogi: Jurnal Pendidikan Islam dan Manajemen Pendidikan Islam, 2(1), 82-95.

Saihu, S. (2020). Pendidikan sosial yang terkandung dalam Surat At-Taubah Ayat 7172. Edukasi Islami: Jurnal Pendidikan Islam, 9(01), 127-148.

Saihu, S. (2020). The Effect of Using Talking Stick Learning Model on Student Learning Outcomes in Islamic Primary School of Jamiatul Khair, Ciledug Tangerang. Tarbawi: Jurnal Keilmuan Manajemen Pendidikan, 6(01), 61-68.

Saihu, S., \& Mailana, A. (2019). Teori pendidikan behavioristik pembentukan karakter masyarakat muslim dalam tradisi Ngejot di Bali. Ta'dibuna: Jurnal Pendidikan Islam, 8(2), 163-176.

Saihu, S., \& Marsiti, M. (2019). PENDIDIKAN KARAKTER DALAM UPAYA MENANGKAL RADIKALISME DI SMA NEGERI 3 KOTA DEPOK, JAWA BARAT. Andragogi: Jurnal Pendidikan Islam dan Manajemen Pendidikan Islam, 1(1), 23-54.

Saihu, S., \& Rohman, B. (2019). PEMBENTUKAN KARAKTER MELALUI MODEL PENDIDIKAN TRANSFROMATIFE LEARNING PADA SANTRI DI PONDOK PESANTREN NURUL IKHLAS BALI. Edukasi Islami: Jurnal Pendidikan Islam, 8(02), 435-452.

Saihu, S., \& Taufik, T. (2019). PERLINDUNGAN HUKUM BAGI GURU. Al Amin: Jurnal Kajian Ilmu dan Budaya Islam, 2(2), 105-116.

Syaifudin, dkk, .Perencanaan Pendidikan Suatu Pendekatan Komprensif. (Bandung: Remaja

Rosdakarya. 2007) hal. 261-263 
